\title{
Computational models of interval timing
}

Q1 Caspar Addyman ${ }^{1}$, Robert M French ${ }^{2}$ and Elizabeth Thomas ${ }^{3}$
In recent years great progress has been made in the computational modeling of interval timing. A wide range of models capturing different aspects of interval timing now exist. These models can be seen as constituting four, sometimes overlapping, general classes of models: pacemakeraccumulator models, multiple-oscillator models, memorytrace models, and drift-diffusion (or random-process) models. We suggest that computational models should be judged based on their performance on a number of criteria - namely, the scalar property, their ability to reproduce retrospective and prospective timing effects, and their sensitivity to attentional and neurochemical manipulations. Future challenges will involve building integrated models and sharing model code to allow direct comparisons against a battery of empirical data.

\begin{abstract}
Addresses
${ }^{1}$ Department of Psychology, Goldsmiths U., London, UK

${ }^{2}$ LEAD-CNRS UMR 5022, U. of Burgundy, Dijon, France

${ }^{3}$ INSERM U1093, U. of Burgundy, Dijon, France
\end{abstract}

Corresponding author: French, Robert M (robert.french@u-bourgogne.fr)

Current Opinion in Behavioral Sciences 2016, 8:xx-yy

This review comes from a themed issue on Timing behavior

Edited by Richard B Ivry and Warren H Meck

doi:10.1016/j.cobeha.2016.01.004

2352-1546/Published by Elsevier Ltd.

Although there are numerous ways in which computational models of interval timing can be classified, we have chosen to group these models into four major, although sometimes overlapping, classes: firstly, pacemaker-accumulator models (PA models), secondly, multiple-oscillator-coincidence detection models (also sometimes called timestamp models), thirdly, memory or neural process models and, finally, fourthly random-process (or drift-diffusion) models. For alternative classification schemes, see, for example $\left[1,2^{\bullet \bullet}\right]$.

In what follows we will suggest that computational models of interval timing be judged on the basis of the following criteria: the scalar property, prospective and retrospective timing, and the effects of attention and neuropharmacological manipulations.

Extensive empirical evidence [3-6] suggests that timeestimation errors in interval timing grow approximately linearly with the size of the estimate. Known as the scalar property of time estimation, this fact sets a hard constraint on the nature of the underlying processes involved in time estimation [7]. This effect has been widely replicated in humans, pigeons, and rodents (see [8-10]. Similar behavioral responses to time scales can even be found in ratedependent habituation in Caenorhabditis elegans [11]. Even though the scalar property has not been found to hold under all conditions [12], modeling it has proved to be a significant challenge for a number of existing models of interval-time judgments [7,13]. In a recent paper, Hass and Hermann [7] use information theoretic arguments to show how the scalar property places several important restrictions on the nature of any interval timing mechanism. Crucially, they argue that, in order to display scalar error profiles, the neural process underlying time perception must be based on a measure of growing variance in the system.

Secondly, it has been established that the perceived passage of time by human adults differs according to whether they are forewarned that they will need to make a timing judgment, and are therefore actively attending to its passage (prospective time estimation), or whether they are required to make an unexpected, after-the-fact judgment of the passage of time (retrospective time estimation). Models should be judged on how well they account for both of these regimes.

And thirdly, there are various systematic effects on the lengths of estimates caused by levels of attention [14] and neurochemistry, such as endogenous levels of dopamine or the effects of dopaminergic drugs [15-17].

We avoided the criterion of 'neurobiological plausibility' because it is notoriously difficult to pin down exactly what is meant by this expression. So, for example, how realistic do computational neurons have to be before the model that uses them can be said to be biologically plausible?

\section{Pacemaker-accumulator models}

The pacemaker-accumulator models (PAM) [18,19 $]$ have had a great influence on the way that experiments on timing are conceived and interpreted. Many of the recent models of timing still utilize the pacemaker and accumulator processes described by Treisman [20]. These models currently constitute the most popular computational approaches to interval timing. In the pacemaker-accumulator model, the arrival of a stimulus starts a clock which generates pulses that are counted by an accumulator. Time judgments are then made by a comparison of what is stored in the accumulator and what is 


\begin{tabular}{|c|c|c|c|c|c|c|c|}
\hline Reference & Model type/Name & What keeps the time? & What tells the time? & Scalar property? & $\begin{array}{l}\text { Neurochemical } \\
\text { or attention } \\
\text { effects? }\end{array}$ & $\begin{array}{l}\text { Prospective } \\
\text { or } \\
\text { retrospective? }\end{array}$ & Comment \\
\hline [18] & $\begin{array}{l}\text { Pacemaker-accumulator: } \\
\text { Scalar Expectancy Theory } \\
\text { (SET) }\end{array}$ & $\begin{array}{l}\text { Poisson process } \\
\text { pacemaker and error free } \\
\text { accumulator }\end{array}$ & $\begin{array}{l}\text { Comparing estimates to } \\
\text { those retrieved from } \\
\text { memory. }\end{array}$ & $\begin{array}{l}\text { Via memory } \\
\text { comparison } \\
\text { not via clock }\end{array}$ & No & Prospective & $\begin{array}{l}\text { The first Pacemaker model to } \\
\text { address the Scalar property. }\end{array}$ \\
\hline [21] & Pacemaker-accumulator & Poisson pacemaker & $\begin{array}{l}\text { Unreliable/stochastic } \\
\text { multistage accumulator }\end{array}$ & $\begin{array}{l}\text { Under special } \\
\text { circumstances }\end{array}$ & No & Prospective & $\begin{array}{l}\text { An unreliable counter } \\
\text { mechanism can give rise to } \\
\text { scalar property under very } \\
\text { narrow circumstances. }\end{array}$ \\
\hline$\left[19^{\circ}, 62\right]$ & Pacemaker-accumulator & $\begin{array}{l}\text { Pacemaker with } \\
\text { geometrically increasing } \\
\text { tick length and Gaussian } \\
\text { noise }\end{array}$ & $\begin{array}{l}\text { Accumulator built into } \\
\text { larger ACT-R model. }\end{array}$ & $\begin{array}{l}\text { Via implausible } \\
\text { pacemaker } \\
\text { assumptions }\end{array}$ & $\begin{array}{l}\text { Attention } \\
\text { effects }\end{array}$ & Prospective & $\begin{array}{l}\text { A classical PAM embedded in } \\
\text { an ACT-R framework models } \\
\text { attention effects as a result of } \\
\text { resource competition. }\end{array}$ \\
\hline [63] & Pacemaker-accumulator & Constant rate pacemaker & $\begin{array}{l}\text { ACT-R model with time } \\
\text { stored in working memory }\end{array}$ & No & $\begin{array}{l}\text { Some } \\
\text { attention } \\
\text { effects }\end{array}$ & Prospective & $\begin{array}{l}\text { Simplistic PAM model built in } \\
\text { ACT-R. }\end{array}$ \\
\hline [22] & Pacemaker-accumulator & Poisson pacemaker & Accumulator and memory & $\begin{array}{l}\text { Via ad hoc } \\
\text { Gaussian } \\
\text { error } \\
\text { mechanism }\end{array}$ & No & Prospective & $\begin{array}{l}\text { Notable for allowing direct } \\
\text { quantitative test of SET by } \\
\text { implementing it in Framsticks } \\
\text { simulation environment. }\end{array}$ \\
\hline [23] & $\begin{array}{l}\text { Multiple-oscillator: beat } \\
\text { frequency }\end{array}$ & $\begin{array}{l}\text { Set of cortical oscillators of } \\
\text { different phase }\end{array}$ & $\begin{array}{l}\text { Time measured by } \\
\text { selecting subset that will } \\
\text { be in phase at correct } \\
\text { interval }\end{array}$ & No & No & Prospective & $\begin{array}{l}\text { Original multiple-oscillator } \\
\text { model. }\end{array}$ \\
\hline$\left[25^{\bullet \bullet}\right]$ & $\begin{array}{l}\text { Multiple-oscillator: striatal } \\
\text { Beat Frequency (SBF) }\end{array}$ & $\begin{array}{l}\text { Set of cortical oscillators of } \\
\text { different phases }\end{array}$ & $\begin{array}{l}\text { Coincidence detectors } \\
\text { based on striatal spiny } \\
\text { neurons }\end{array}$ & $\begin{array}{l}\text { Only under } \\
\text { assumption } \\
\text { of globally } \\
\text { correlated } \\
\text { phase } \\
\text { variations }\end{array}$ & $\begin{array}{l}\text { Several } \\
\text { neurochemical } \\
\text { effects }\end{array}$ & Prospective & $\begin{array}{l}\text { A modern oscillator model } \\
\text { that takes good account of } \\
\text { neuroscience evidence. }\end{array}$ \\
\hline$\left[26^{\bullet \bullet}, 27\right]$ & $\begin{array}{l}\text { Multiple-oscillator: SBF } \\
\text { with realistic noisy neurons }\end{array}$ & $\begin{array}{l}\text { Set of cortical oscillators } \\
\text { with different phases and } \\
\text { uncorrelated noise }\end{array}$ & $\begin{array}{l}\text { Neural network } \\
\text { 'coincidence detector' }\end{array}$ & Yes & $\begin{array}{l}\text { Yes-numerous } \\
\text { pharmacological } \\
\text { effects. }\end{array}$ & Prospective & $\begin{array}{l}\text { A nice reinvention of SBF } \\
\text { where scalar property } \\
\text { emerges naturally from } \\
\text { network noise. }\end{array}$ \\
\hline$[11,34]$ & $\begin{array}{l}\text { Memory decay: multiple } \\
\text { time scales (MTS) }\end{array}$ & $\begin{array}{l}\text { Chain of decaying } \\
\text { activations }\end{array}$ & $\begin{array}{l}\text { Reading off absolute level } \\
\text { of decay }\end{array}$ & $\begin{array}{l}\text { By assuming } \\
\text { fixed Gaussian } \\
\text { error threshold }\end{array}$ & No & Prospective & $\begin{array}{l}\text { First memory decay model } \\
\text { was actually model of } \\
\text { habituation in C. elegans. Only } \\
\text { models prospective timing } \\
\text { because requires dedicated } \\
\text { mechanism. }\end{array}$ \\
\hline$\left[36^{\circ}\right]$ & $\begin{array}{l}\text { Memory decay: Gaussian } \\
\text { Activation Model (GAMIT) }\end{array}$ & $\begin{array}{l}\text { Spreading cortical } \\
\text { activation from event to be } \\
\text { timed and rate of change of } \\
\text { activation. }\end{array}$ & $\begin{array}{l}\text { Comparison of activation } \\
\text { to learned reference curve }\end{array}$ & Yes & $\begin{array}{l}\text { Cognitive load } \\
\text { effects via } \\
\text { attentional } \\
\text { resource } \\
\text { competition }\end{array}$ & Both & $\begin{array}{l}\text { Retrospective case a single } \\
\text { estimate is made at end of } \\
\text { interval. In prospective case } \\
\text { multiple estimates during } \\
\text { interval contribute. }\end{array}$ \\
\hline [37] & $\begin{array}{l}\text { Memory decay: GAMIT- } \\
\text { Net }\end{array}$ & $\begin{array}{l}\text { Spreading cortical } \\
\text { activation }\end{array}$ & $\begin{array}{l}\text { Neural network learns to } \\
\text { estimate time }\end{array}$ & Yes & $\begin{array}{l}\text { Attention effects } \\
\text { via resource } \\
\text { competition }\end{array}$ & Both & $\begin{array}{l}\text { Neural network version of } \\
\text { GAMIT model. }\end{array}$ \\
\hline
\end{tabular}




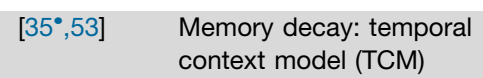

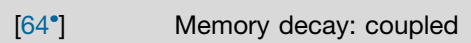

leaky integrators

[38] Climbing activation

[65] Climbing activation: Dual klepsydra model

$\left[42^{\circ}, 43\right] \quad$ Climbing activation: evolved, embodied neural net model. neuron systems acts like a simple oscillator.

Firing rate adaptation in inhibitory neurons leads to increasing activity in

excitatory neurons.

Leaky integrator

An evolved continuous time recurrent neural network

Population of independent

Random process:

population of bistable units bistable units transitioning from off to on

[46,47 $\left.{ }^{\circ \bullet}\right] \quad$ Random process: driftdiffusion model of interval timing \& decision making

Random walk by competing random inhibitory and excitatory processes.

[66] Contextual change Estimates derived from amount of activity, number of actions and ACT-R system time. etwork has wait o

No

When active population crosses fixed threshold.

Changes to adaptation rate

change interval

Comparing one integrator No

to another

Networks seemed to work No

via climbing activation.

No

Yes

When number of ON

neurons crosses threshold

Yes

When total crosses

particular threshold.

Yes

ACT-R model
No

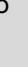

Prospective

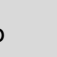

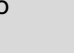

Prospective

Prospective

Prospective

Prospective

No

Some
attention
effects

effects

Retrospective
Adapts model of serial memory performance to more general task of interval timing. Estimation method is relatively complex approximate inverse Laplace Transform.

A very simple neural system model animal learning data. Noise plays important role in stabilizing network behavior. Detailed neural model inspired by recordings from macaque inferotemporal cortex.

Unclear why integrator values cannot be accessed directly. Evolved neural network with standard leaky-integrator neurons tells time without clock-like control a robot in a simulated environment.

Different intervals measured by different global transition probabilities. Not clear how this would be implemented.

An probabilistic model than accounts for decision making and interval production in same framework.

Underspecified mechanism

but embedding model in ACT-

$R$ framework allowed testing

of attention effects. 
stored in memory. Gibbon's Scalar Expectancy Theory (SET) model emphasized the importance of reproducing the property of scale invariance observed in interval timing [3,18]. Scalar error in this model arises not from the clock itself but rather from noise in the comparison process. Several variants on this original pacemakeraccumulator design have been produced. For example, Killeen and Taylor [21] use a different approach to the scalar property by using a noisy accumulator process Q2 rather than a noisy comparator (Table 1).

Recent models have taken the pacemaker-accumulator process and incorporated it into a larger cognitive system. For example, Taatgen et al. $\left[1^{\circ}\right]$ place a timekeeping module in the context of a general ACT-R architecture to capture the effects of attention and resource competition on interval timing. This model incorporates an attentional gate which modulates the rate of pulse accumulation hence leading to changes in the perception of intervals. Another example is Komosinski and Kups [22] who build a classical PAM in a neural simulator environment to model time-judgment errors in successively presented time intervals.

One difficulty with these models is that errors in sequential processes grow too slowly (as the square root of length of the interval). Any timer based on direct accumulation of ticks would be too accurate. In order to account for the scalar property of time, pacemaker-accumulator models have to introduce a secondary source of multiplicative error in the comparison process [7].

\section{Multiple-oscillator models}

Multiple-oscillator models [23,24] refer to models of interval timing in which intervals are represented as a set of activities of several oscillators. An early form of the model was developed by Miall [23]. In this model, referred to as the beat frequency (BF) model, timing is carried out by the activation of several oscillators, each of which oscillates at its own particular frequency. The arrival of a stimulus resets the oscillators so that they begin to fire together. The time elapsed since the arrival of the stimulus would then depend on the oscillatory phases of the entire set of oscillators. However the distribution of firing was not normally distributed, having a sharp peak at the target time and smaller peaks at the major harmonics of the fundamental interval. In addition, the width of the peak was not proportional to the length of the interval. For this reason, and because the model did not contain any noise, it was unable to account for the property of scalar invariance.

The Striatal Beat-Frequency (SBF) model tried to address these problems $\left[25^{\circ}\right]$. They modified the BF to induce the scalar property. The SBF model took into account experimental findings that interval timing was not exclusively the result of activity in the basal ganglia but also of activity in a thalamo-cortico-striatal circuit. In this model, oscillations are generated by cortical neurons and timing is indicated by the coincidental activation of spiny neurons in the striatum of the basal ganglia by the cortical oscillators. Oscillator speeds and neuronal firing thresholds were adjusted on a trial by trail basis in order to reproduce the Gaussian shaped response profiles seen in timing experiments that use the peak procedure experimental method and thereby produce scalar invariance. However, these adjustments had to be globally coherent, otherwise the coincidence-detections mechanisms would not operate appropriately. This tends to make the SBF model oversensitive to small amounts of noise.

Improvements to the SBF model have been made by $\left[26^{\bullet}, 27\right]$. This model retained the separation of cortical and striatal roles used in the SBF models. The neurons in the new models however, were far more realistic. The simpler neuronal models were replaced by more detailed Morris-Lecar neurons and neural activity was now the result of the dynamics in several ionic channels. This model succeeded in replicating several experimental findings on the effects of dopamine and cholinergic agents on timekeeping. In a more generalized version of the model in which a perceptron replaced the striatum and its coincidence detection, scalar errors were an emergent property of the network without the need for global coherence $\left[26^{\circ \bullet}\right]$. The SBF model has also been extended to include a unified account of duration-based and beatbased timing mechanisms [28,29].

\section{Memory-based models}

A third class of models relies on memory decay and falling (or rising) neural activation. These neural processes are relatively well understood and provide evidence that timing and memory use the same cognitive resources [30], recruiting neurons in the dorso-lateral prefrontal cortex [31-33]. Once again, the scalar property does not always arise from these models in a straightforward manner. For example, the Multiple Time Scales model (MTS, $[11,34])$ relies on a series of leaky integrators with power law decay and these integrators must be carefully linked to approximate the required logarithmic decay function. The Temporal Context Model (TCM, $\left[35^{\circ}\right]$ ) relies on many leaky integrators and far more complex dynamics than the MTS model.

Computational memory models have been introduced which take into account not only the amount of activation decay of a memory trace but also the rate at which activation decays (GAMIT: $\left[36^{\bullet \bullet}, 37\right]$ ). In this model, there is a mechanism of attentional-resource sharing that allows GAMIT to model both retrospective and prospective timing.

By contrast with these falling activation-trace models, Reutimann et al. [38] use a single climbing neuronal trace 
that attains a threshold at the expected end of an interval. This model [38] is built on a single mechanism using well-understood principles of synaptic plasticity and the decision rule is built into the model itself. Single cell recordings in the inferotemporal cortex of monkeys have, in fact, found neurons with the appropriate time-dependent firing rates [39,40]. This interpretation of climbing activation remains controversial, however, see [41].

An interesting recent addition to this class is $\left[42^{\circ}, 43\right]$, in which neural networks with standard leaky-integrator neurons were evolved to control a robot in a simulated environment in order to perform a temporal comparison task. When network activity was examined timing appeared to be due to a climbing activation mechanism.

\section{Random process models}

Models discussed so far have been broadly deterministic or based on probabilistic processes (e.g. counting random ticks) that produce time estimates that have less than scalar error. The models in this section are based on probabilistic processes with linear or greater than linear error. The simplest approach [44] replaces a single Poisson process with a group of 100 independent Poisson process and a leaky integrate-and-fire neuron that fires and resets every time it crosses a threshold. With a fixed threshold this model underestimates intervals but improves with the incorporation of a dynamic threshold that is inhibited by recent firings. However, the actual fit to empirical data remains poor. A better fit to data is obtained by [45] in which a timer starts by setting 50 bistable units to 'off'. Thereafter, each bistable unit transitions to 'on' independently with probability $p$ (adjusted by learning) and the timer stops when a total of 40 units are active.

If excitatory and inhibitory processes both contribute to the same integrator then, unless the processes are precisely balanced, the resulting random walk will drift in one direction. Adjusting the balance adjusts the rate of drift allowing different intervals to be learned $\left[46,47^{\bullet \bullet}\right]$. The learning process is simpler than in [45] because it does not rely on fine tuning a group of probabilities. The approach has additional advantages that the same framework can model decision making and that it makes several quite precise predictions about skew and coefficients of variation of responses in temporal reproduction tasks.

Finally, it should be noted that in subsecond timing most successful models are random-process models, based on stochastically connected chains of noisy neurons $\left[48,49^{\bullet}, 50\right]$. However, most authors do not think that these models can be extended to the multi-second domain of interval timing [51]. This inability to scale up to multi-second timing applies only to these random-process models. It remains an open question as to whether other classes of models can account for both subsecond and multi-second timing.

\section{Difficulties with the models}

As currently implemented pacemaker-accumulator and multiple-oscillator models rely on a dedicated timing mechanism which needs to be started when a particular event occurs. This is problematic for retrospective timing because all perceived events are potential candidates for retrospective time judgments and, therefore, each event would require a separate timer.

Staddon [52] suggested that memory-trace models could overcome this reset problem because all perceived events encoded by the cognitive system automatically result in representations that are governed by the same trace dynamics. However, most activation-trace models posit a specialist timing mechanism that is only recruited when timing is required (e.g. [34,38]) and models of this type can only address prospective timing. The Temporal Context Model (TCM) [35 $5^{\circ}$ developed from a model of episodic memory, can potentially perform both retrospective and prospective timing. To the best of our knowledge, TCM is the first attempt to use features of memory directly as a mechanism for interval timing. GAMIT $\left[36^{\bullet}\right]$ has similar motivations but is much simpler than TCM.

Our estimates of time passing can also be affected by whether or not we are actively attending to the passage of time and by cognitive load. Block et al. [14] found that high cognitive load increases retrospective time estimates and decreases prospective time estimates. Modeling this surprising effect is a challenge for all existing models of interval timing. French et al. [36 $\left.{ }^{\bullet \bullet}\right]$ suggest an attentional resource-sharing mechanism that allows prospective and retrospective timing to be accounted for in a single model. Moreover, this model, GAMIT [36 $6^{\bullet \bullet}$, is currently the only computational model to account for this interaction.

Most models simply do not consider attentional effects on interval time perception $[34,38,53]$. One simple proposal is that attention might modulate clock speed directly $\left[25^{\bullet}\right]$. If decreased attention to timing causes the organism's internal clock to beat slower, then it will tend to underestimate the length of intervals. This idea is developed further in the time-sharing model [54]. Working memory, timing and attention all depend on dopaminergic pathways $[32,55,56]$. The changes observed in interval timing estimates following pharmacological interventions that modulate clock speed [16,57] have been modeled by letting dopamine levels affect oscillator frequency (e.g. $\left.\left[26^{\bullet}, 27,58\right]\right)$. Nevertheless, none of these models can account for the increase in retrospective estimates under high cognitive load. 
Far fewer models attempt to explain retrospective timing, in part because retrospective timing does not have an equivalent in animal behavior. A common theme behind all approaches to retrospective timing is that intervals are estimated by reconstructing a sequence of remembered events. Cognitive load could affect this by changing the memorability or numerosity of events $[59,60]$.

\section{Future challenges}

In conclusion, computational models of interval timing have come a long way but are still faced with many challenges. Besides the difficulties already discussed, a genuinely mature model needs to:

- fit individual not just group data

- give a coherent account of relationship between retrospective and prospective timing,

- apply to the full range of timing tasks and their associated attentional and pharmacological modulations,

- explain commonalities and differences between animal and human time perception.

We have argued elsewhere [61] that modelers need to make their code available and user accessible so that their models can be directly compared and developed. The current variety of modeling approaches is a strength. Bringing the successes of these varied models into a comprehensive framework is the long term goal for the field.

\section{Conflicts of interest}

Nothing declared.

\section{Acknowledgments}

Q3 This work was supported in part by a grant from the French Agence Nationale de la Recherche (ANR-14-CE28-0017) to the second author, by a joint grant from the ANR (ANR-10-056 GETPIMA) to the second and third authors, and the UK ESRC (RES-062-23-0819) to the first author, within the framework of the Open Research Area (ORA) France - UK funding initiative.

\section{References and recommended reading}

Papers of particular interest, published within the period of review, have been highlighted as:

- of special interest

$\bullet$ of outstanding interest

1. Anamalamudi K, Surampudi BR, Maganti M: Computational models of time perception. In Proceedings of the First International Conference on Networks \& Soft Computing (ICNSC); 19-20 Aug. 2014, Guntur, Andhra Pradesh, India: 2014:413-417.

2. Hass J, Durstewitz D: Neurocomputational models of time

-. perception. In Neurobiology of Interval Timing, vol. 829 no. JANUARY 2014. Edited by Merchant V, de Lafuente. Springer Science+Business Media; 2014

A detailed review of interval timing models.

3. Gibbon J: Scalar expectancy theory and Weber's law in animal timing. Psychol Rev 1977, 84:279-325.

4. Matell MS, Meck WH: Neuropsychological mechanisms of interval timing behavior. BioEssays 2000, 22:94-103.
5. Grondin S: Timing and time perception: a review of recent behavioral and neuroscience findings and theoretical directions. Attention Percept Psychophys 2010.

6. Buhusi CV, Meck WH: What makes us tick? Functional and neural mechanisms of interval timing. Nat Rev Neurosci 2005, 6:755-765.

7. Hass J, Herrmann JM: The neural representation of time: an information-theoretic perspective. Neural Comput 2012, 24:1519-1552.

8. Buhusi CV, Aziz D, Winslow D, Carter RE, Swearingen JE, Buhusi MC: Interval timing accuracy and scalar timing in C57BL/6 mice. Behav Neurosci 2009, 123:1102-1113.

9. Gibbon J, Malapani C, Dale CL, Gallistel CR: Toward a neurobiology of temporal cognition: advances and challenges. Curr Opin Neurobiol 1997, 7:170-184.

10. Malapani $\mathrm{C}$, Fairhurst S: Scalar timing in animals and humans. Learn Motiv 2002, 33:156-176.

11. Staddon JE, Higa JJ: Multiple time scales in simple habituation. Psychol Rev 1996, 103:720-733.

12. Wearden $\mathrm{JH}$, Lejeune $\mathrm{H}$ : Scalar properties in human timing: conformity and violations. $Q J$ Exp Psychol 2008, 61:569-587.

13. Shi Z, Church RM, Meck WH: Bayesian optimization of time perception. Trends Cogn Sci 2013, 17:556-564.

14. Block RA, Hancock PA, Zakay D: How cognitive load affects duration judgments: a meta-analytic review. Acta Psychol (Amst) 2010, 134:330-343.

15. Cheng RK, MacDonald CJ, Meck WH: Differential effects of cocaine and ketamine on time estimation: Implications for neurobiological models of interval timing. Pharmacol Biochem Behav 2006, 85:114-122.

16. Meck WH: Neuropharmacology of timing and time perception. Cogn Brain Res 1996, 3:227-242.

17. Jones $C R G$, Jahanshahi M: Contributions of the basal ganglia to temporal processing: evidence from Parkinson's disease. Timing Time Percept 2014, 2:87-127.

18. Gibbon J: Ubiquity of scalar timing with a Poisson clock. J Math Psychol 1992, 36:283-293.

19. Taatgen NA, van Rijn H, Anderson J: An integrated theory of - prospective time interval estimation: the role of cognition, attention, and learning. Psychol Rev 2007, 114:577-598.

A classical PAM embedded in an ACT-R framework, nicely demonstrates attention effects as a result of resource competition.

20. Treisman $\mathrm{M}$ : Temporal discrimination and the indifference interval: Implications for a model of the'internal clock'. Psychol Monogr Gen Appl 1963, 77:1-31.

21. Killeen PR, Taylor TJ: How the propagation of error through stochastic counters affects time discrimination and other psychophysical judgments. Psychol Rev 2000, 107:430-459.

22. Komosinski M, Kups A: Time-order error and scalar variance in a computational model of human timing: simulations and predictions. Comput Cogn Sci 2015, 1:3.

23. Miall $\mathrm{C}$ : The storage of time intervals using oscillating neurons. Neural Comput 1989.

24. Church RM, Broadbent $\mathrm{HA}$ : Alternative representations of time, number, and rate. Cognition 1990, 37:55-81.

25. Matell MS, Meck WH: Cortico-striatal circuits and interval

-. timing: coincidence detection of oscillatory processes. Cogn Brain Res 2004, 21:139-170.

The Striatal Beat Frequency model: a classic reference in multipleoscillator models.

26. Buhusi CV, Oprisan SA: Time-scale invariance as an emergent - property in a perceptron with realistic, noisy neurons. Behav Processes 2013, 95:60-70.

An implementation of Striatal Beat Frequency model that has a scalar property. 
27. Oprisan SA, Buhusi CV: Modeling pharmacological clock and memory patterns of interval timing in a striatal beat-frequency model with realistic, noisy neurons. Front Integr Neurosci 2011 5:1-11.

28. Allman MJ, Teki S, Griffiths TD, Meck WH: Properties of the internal clock: first- and second-order principles of subjective time. Annu Rev Psychol 2014, 65:743-771.

29. Teki S, Grube M, Griffiths TD: A unified model of time perception accounts for duration-based and beat-based timing mechanisms. Front Integr Neurosci 2011, 5:90.

30. Fortin C, Rousseau R: Interference from short-term memory processing on encoding and reproducing brief durations. Psychol Res 1998, 61:269-276.

31. Genovesio A, Tsujimoto S, Wise SP: Neuronal activity related to elapsed time in prefrontal cortex. J Neurophysiol 2006, 95: 3281-3285.

32. Lustig C, Matell MS, Meck WH: Not 'just' a coincidence: frontalstriatal interactions in working memory and interval timing. Memory 2005, 13:441-448.

33. Wager TD, Smith EE: Neuroimaging studies of working memory: a meta-analysis. Cogn Affect Behav Neurosci 2003 , 3:255-274.

34. Staddon JE, Higa JJ: Time and memory: towards a pacemaker-free theory of interval timing. J Exp Anal Behav 1999, 71:215-251.

35. Shankar $\mathrm{KH}$, Howard MW: Timing using temporal context. Brain Res 2010, 1365:3-17.

Adapts a model of episodic memory to give time estimates without explicit timing mechanism.

36. French RM, Addyman C, Mareschal D, Thomas E: GAMIT - a

-• fading-gaussian activation model of interval-timing: unifying prospective and retrospective time estimation. Timing Time Percept Rev 2014, 1:1-17.

Memory decay model that accounts for retrospective and prospective timing in the same framework.

37. Addyman C, Mareschal D: GAMIT-Net: retrospective and prospective interval timing in a single neural network. In Proceedings of the 36th Annual Conference of the Cognitive Science Society. 2014:98-103.

38. Reutimann J, Yakovlev V, Fusi S, Senn W: Climbing neuronal activity as an event-based cortical representation of time. $J$ Neurosci $2004,24: 3295-3303$.

39. Komura Y, Tamura R, Uwano T, Nishijo H: Retrospective and prospective coding for predicted reward in the sensory thalamus. Nature 2001

40. Leon M, Shadlen M: Representation of time by neurons in the posterior parietal cortex of the macaque. Neuron 2003.

41. Kononowicz $\mathrm{T}$, van Rijn $\mathrm{H}$ : Tonic and phasic dopamine fluctuations as reflected in beta-power predict interval timing behavior. Procedia-Social Behav Sci 2014.

42. Maniadakis $M$, Trahanias $P$ : Experiencing and processing time - with neural networks. Cogn. 2012, Fourth ..., no. c. 2012:145-150. Evolved neural network with standard leaky-integrator neurons tells time without clock-like mechanisms.

Q5 43. Maniadakis $M$, Trahanias $P$ : Artificial agents perceiving and processing time, 2015

44. Anamalamudi K, Surampudi BR, Maganti M: Stochastic leaky integrator model for interval timing. In Proceedings of the Multidisciplinary Trends in Artificial Intelligence 8th International Workshop, MIWAI 2014; Bangalore, India, December 8-10, 2014: 2014.

45. Almeida R, Ledberg A: A biologically plausible model of timescale invariant interval timing. J Comput Neurosci 2010, 28 : $155-175$
46. Simen P, Balci F, DeSouza L, Cohen JD, Holmes P: A model of interval timing by neural integration. $J$ Neurosci $2011,31: 9238$ 9253.

47. Simen P, Vlasov K, Papadakis, S: Scale (In) Variance in a Unified - Diffusion Model of Decision Making and Timing, Psychol Rev A drift diffusion model than accounts for decision making and interval production in same framework.

48. Hass J, Blaschke S, Rammsayer T, Herrmann JM: A neurocomputational model for optimal temporal processing. $J$ Comput Neurosci 2008, 25:449-464.

49. Buonomano DV, Merzenich MM: Temporal information

- transformed into spatial code by neural network with realistic properties. Science (80-) 1995, 42 541-541.

Subsecond timing without specialized mechanisms, timing emerges from dynamics of recurrent neural network.

50. Buonomano DV: A learning rule for the emergence of stable dynamics and timing in recurrent networks. J Neurophysiol 2005, 94:2275-2283.

51. Karmarkar UR, Buonomano DV: Timing in the absence of clocks: encoding time in neural network states. Neuron 2007 , 53:427-438.

52. Staddon JER: Interval timing: memory, not a clock. Trends Cogn Sci 2005, 9:312-314.

53. Howard MW, Shankar KH, Aue WR, Criss AH: A distributed representation of internal time. Psychol Rev 2015, 122:24-53.

54. Buhusi CV, Meck WH: Interval timing with gaps and distracters: evaluation of the ambiguity, switch, and time-sharing hypotheses. J Exp Psychol Anim Behav Process 2006, 32:329-338.

55. Cools R, D'Esposito M: Inverted-u-shaped dopamine actions on human working memory and cognitive control. Biol Psychiatry 2011, 69:e113-e125.

56. Lake Jl, Meck WH: Differential effects of amphetamine and haloperidol on temporal reproduction: dopaminergic regulation of attention and clock speed. Neuropsychologia 2013, 51:284-292.

57. Coull JT, Cheng R-K, Meck WH: Neuroanatomical and neurochemical substrates of timing. Neuropsychopharmacology 2011, 36:3-25.

58. Allman MJ, Meck WH: Pathophysiological distortions in time perception and timed performance. Brain 2012, 135:656-677.

59. Poynter WD: Duration judgment and the segmentation of experience. Mem Cognit 1983, 11:77-82.

60. Zakay D, Block Ra: Prospective and retrospective duration judgments: an executive-control perspective. Acta Neurobiol Exp (Wars) 2004, 64:319-328.

61. Addyman $\mathrm{C}$, French RM: Computational modeling in cognitive science: a manifesto for change. Top Cogn Sci 2012, 4:332-341.

62. Taatgen NA, Van Rijn H, Anderson J: Time perception: Beyond simple interval estimation. In Proceedings of the Sixth International Conference on Cognitive Modeling Pittsburgh, vol 12. 2004:296-301.

63. Pape N, Urbas L: A model of time-estimation considering working memory demands. Proc. 30th Annu. Cogn. Sci. Soc.. 2008.

64. Dragoi V, Staddon JER, Palmer RG, Buhusi CV: Interval timing as - an emergent learning property. Psychol Rev 2003, 110:126-144. A very simple neural system model that provides a good fit animal learning data. Noise plays important role in stabilizing network behavior.

65. Wackermann J, Ehm W: The dual klepsydra model of internal time representation and time reproduction. J Theor Biol 2006.

66. Dzaack J, Trösterer S, Pape N, Urbas L: A computational model of retrospective time estimation. Cogn Syst Res 2007. 